\title{
Do bocado ao pastoreio de precisão: compreendendo a interface planta- animal para explorar a multi-funcionalidade das pastagens
}

\author{
Paulo César de Faccio Carvalho ${ }^{1}$, Julio Kuhn da Trindade ${ }^{2}$, Jean Carlos Mezzalira ${ }^{2}$, \\ Cesar Henrique Espírito Candal Poli ${ }^{1}$, Carlos Nabinger, Teresa Cristina Moraes Genro ${ }^{3}$, \\ Horacio Leandro Gonda 4
}

\footnotetext{
1 Faculdade de Agronomia, Depto. de Plantas Forrageiras e Agrometeorologia da UFRGS, Cx. Postal 776, CEP: $91501-970$.

2 Programa de Pós-Graduação em Zootecnia/UFRGS, Depto. de Plantas Forrageiras e Agrometeorologia, Cx. Postal 776, CEP: $91501-970$

${ }^{3}$ EMBRAPA - CPPSUL, Bage.

4 UNCPBA, Tandil, Argentina.
}

RESUMO - A pecuária de precisão diz respeito a inovações tecnológicas que monitoram o animal no seu ambiente pastoril. O comportamento ingestivo do animal é a base do conhecimento necessário para proceder às ações de manejo decorrentes do monitoramento dos animais e da vegetação. Como serão utilizadas as informações geradas pelas tecnologias ainda é uma incógnita. Na agricultura de precisão, a prerrogativa tem sido corrigir a variabilidade e padronizar a produção em patamares maximizados. É discutido que a mesma lógica, aplicada a pecuária, pode acentuar incorreções clássicas no manejo do pastejo. Não obstante, se a pecuária de precisão vier para ajudar a integrar a heterogeneidade na condução dos animais nos pastos, então podemos estar diante de uma poderosa ferramenta para responder aos novos paradigmas da multifuncionalidade das pastagens. Este artigo discute este contexto, e traz o bocado como a unidade básica do processo a ser monitorado. Alguns equipamentos e suas aplicações no monitoramento do uso de sítios e da dinâmica espaço-temporal dos bocados são apresentados. Conclui-se exemplificando como criar ambientes pastoris com bocados de precisão, e como construir estruturas de pasto para alocar bocados.

Palavras-chave: bocado, estrutura do pasto, manejo de pastagens, pastejo, pecuária de precisão

\section{From the bite to precision grazing: understanding the plant-animal interface to exploit the multi-functionality of grasslands}

\begin{abstract}
Precision livestock involves innovative technologies to monitor the animal within its pastoral environment. Understanding ingestive behaviour is fundamental to management decisions based upon animal and vegetation monitoring. The way such information can be used is not yet clear. In precision agriculture, the governing principle has been to correct or manage variability so as to homogenise yield at maximized levels. If the same reasoning is applied in livestock production, it can foster classical mistakes in grazing management. However, if precision livestock production can help integrate heterogeneity in managing animals on pasture, then we have a powerful new tool for responding to the new paradigms involving the multi-functionality of grasslands. This paper discusses this concept, and presents the bite as the basic unit of the process to be monitored. A few types of equipment and their application in monitoring site use and the spatial-temporal dynamics of animal biting are presented. The discussion concludes with how to build pastoral environments with precision bite management, and how to create sward structures to influence the temporal and spatial dynamics of animal biting.
\end{abstract}

Key Words: bite, grazing, pasture management, precision livestock, sward structure

\section{Introdução}

A pecuária de precisão, no contexto dos ecossistemas pastoris, é a forma moderna de gerenciar os sistemas de produção animal a pasto. Consiste na medição de diferentes parâmetros dos animais, a modelagem desses dados para selecionar a informação que se quer, e o uso desses modelos em tempo real visando o monitoramento e o controle de animais e rebanhos (Berckmans, 2008). A pecuária de precisão integra os conhecimentos de comportamento animal, a tecnologia eletrônica e os sistemas de decisão aplicados ao pastoreio (Laca, 2008). O fundamento está em conhecer o comportamento em pastejo dos animais e saber por que, e como, modificá-lo. O condicionamento do comportamento ingestivo, via treinamento dos animais com recompensas e criação de 
aversões, as cercas virtuais, oaumento do valor percebido dos sítios de pastejo são exemplos, dentre vários, de ferramentas de precisão que podem ser usadas no manejo de ambientes pastoris.

No interesse de consultar o tema sobre pecuária de precisão de forma mais extensa, o leitor é referido a Laca (2009a). Neste trabalho faremos a distinção entre a pecuária de precisão e o pastoreio ${ }^{1}$ de precisão, para poder tratar este último referindo-se exclusivamente ao manejo e ao controle do processo de pastejo via ferramentas tecnológicas, ou pelo menos algumas, que têm sido utilizadas para monitorar os padrões de pastejo dos animais. Parte-se do princípio de que a base da pecuária de precisão esteja no conhecimento do processo de pastejo, que por sua vez tem como unidade básica o bocado, daí a concepção deste trabalho. Propomo-nos, inicialmente, a uma discussão sobre as motivações e usos da pecuária e do pastoreio de precisão, e posteriormente apresentamos alguns resultados de comportamento em pastejo que ilustram o potencial de seu monitoramento e controle.

\section{Novos paradigmas para o manejo das pastagens}

A pecuária de precisão, em conjunto com a perspectiva multi-funcional das pastagens (Hervieu, 2002) englobando tanto a produção animal quanto os serviços ambientais, resulta em novo paradigma para o manejo e a utilização dos ambientes pastoris ${ }^{2}$, onde os objetivos e meios transcendem a meta da simples produção animal perseguida até os tempos recentes.

Os desafios para a utilização de ruminantes em pastagens muito se modificaram nos últimos anos. De forma geral, a busca por recordes de produtividade animal dá lugar cada vez mais a necessidades de explicar e justificar o processo produtivo (Carvalho, 2005). Houve tempo em que a produção de ruminantes em pastagens era, por si só, um sistema de produção reconhecido como ecologicamente correto. Não é mais. Contou definitivamente, para tanto, a recente e controversa publicação da FAO de 2005 intitulada “Livestock's Long Shadow", que culpou os ruminantes pelas emissões de cerca de $1 / 3$ do metano emitido no mundo. O Brasil, e seus quase 200 milhões de bovinos, passaram a estar sob vigilância ecológica mundial, com reflexos evidentes sobre as relações comerciais futuras para a comercialização dos produtos animais oriundos de pastagens.

E o que este contexto traz para o manejo das pastagens? Resulta que as pastagens não são mais apenas produtoras de produto animal. Além disso, têm que ser reconhecidas dentro de uma visão holística, cujo papel ultrapassa a simples produção e se integra na expectativa de serviços ecossistêmicos, destacando-se a regulagem dos ciclos biogeoquímicos ( $\mathrm{C}, \mathrm{N}, \mathrm{H}_{2} \mathrm{O}$, P, etc.), abrigando populações de diversos invertebrados que têm um papel importante nos ciclos de carbono e nitrogênio, sobretudo, bem como de aves e mamíferos para os quais a pastagem é fonte de alimento e de abrigo. Enfim, um habitat multi-funcional (Lemaire et al., 2003).

Nesse contexto, o manejo de pastagens passa a fazer face a novos paradigmas. Hervieu (2002) destaca que o manejo dos pastos deva levar em conta o atributo de multifuncionalidade das pastagens, que ilustra a nova expectativa que as sociedades têm para com o ambiente pastoril. Dentre tais expectativas destacam-se a construção e a ocupação da paisagem, a preservação de biodiversidade, o suporte a sistemas agrícolas no manejo de efluentes, o papel de vetor de imagens de produtos ecologicamente corretos e de base para sistemas de produção animal mais sustentáveis e independentes, dentre outros. A conseqüência concreta dessa expectativa para o manejo das pastagens é inquietante para a filosofia atual de exploração das pastagens no Brasil e em muitos países que ainda se encontram na "era produtivista". Isto porque significaria o abandono da procura pela homogeneidade e a estabilidade, da procura pelo potencial produtivo imediato, e uma aceitação de sistemas de produção mais heterogêneos e diversificados, dentro de uma perspectiva de produção de médio e longo prazo, incluindo-se metas ambientais (Carvalho, 2005).

O bovino, neste contexto, não mais tem mais por objetivo a simples colheita de forragem e sua transformação em produto animal. Na perspectiva de estar trabalhando em ambientes pastoris, onde o papel do herbívoro é ocupado pelo ruminante doméstico, os bovinos, ovinos e caprinos têm responsabilidades junto ao fluxo de nutrientes, com a atividade e diversidade da microbiota do solo, com a mesofauna, com a estrutura da vegetação, etc. Enfim, os ruminantes se tornam engenheiros do ecossistema (sensu Derner et al., 2009), cujo manejo passa a almejar a construção de ambientes pastoris multi-funcionais via controle do pastejo, seu impacto na vegetação e, por conseguinte, no funcionamento do ecossistema (Carvalho, 2005).

Portanto, a própria gestão do animal em seu ambiente de pastejo passa a compor um contexto mais complexo do que a simples determinação, por exemplo, do tipo animal

\footnotetext{
${ }_{2}^{1}$ Pastoreio refere-se à ação antrópica de condução do processo de pastejo.

${ }^{2} \mathrm{O}$ termo pastagem refere-se a situações em que o manejo das relações planta-animal objetive quase que exclusivamente a produção animal, enquanto o termo ambiente pastoril refere-se a situações de utilização do recurso forrageiro que objetivem tanto a produção animal quanto a produção de serviços ambientais.
} 
(demanda e nicho alimentar), da carga (intensidade de pastejo) e de sua distribuição (métodos de pastejo). Exige novos conceitos de manejo e novas ferramentas para fazer frente a esses novos paradigmas. Segundo Laca (2009b), há necessidade de se incorporar a heterogeneidade e escalas não lineares de interações ecológicas que são variáveis no tempo e no espaço, tais como a seleção de dietas e o processo de desfolhação, isso se quiser que se promovam progressos no manejo de pastagens. Seria neste contexto que o pastoreio de precisão estaria evoluindo?

Pecuária de precisão, pastoreio de precisão, bocados de precisão e objetivos imprecisos...

Segundo Hacker et al. (2008), a pecuária de precisão permite manejar os recursos forrageiros de tal forma a compatibilizar o suprimento de forragem com a demanda dos animais. Tal objetivo não é uma novidade. A novidade está na possibilidade de se poder atingi-lo pelo gerenciamento do sistema a partir de telemetria. Para tanto, a base da proposição da pecuária de precisão estaria no monitoramento individual e remoto dos animais e das pastagens, o que a tecnologia recente está cada vez mais nos oferecendo.

A pecuária de precisão, pela integração das novas tecnologias com o conhecimento do comportamento animal, pode reduzir impactos ambientais negativos como o sobrepastejo (Laca, 2009a). Páscoa \& Costa (2007) ilustraram como aplicar o SIG (Sistema de Informação Geográfica) na interpretação dos padrões de uso de sítios dentro de uma pastagem. De fato, as aplicações dessas tecnologias são potencialmente imensas, inclusive podendo contribuir para a rastreabilidade dos produtos, uma vez que oferece registros quanto a origem dos produtos e o seu meio de produção (Laca, 2009a).

Dentre exemplos da aplicação dos conceitos de pecuária de precisão em sistemas de produção estão os cochos, comedouros e aguadas de controle remoto que visam interferir na distribuição espacial do pastejo. Informações sobre a posição dos animais são obtidas por GPS (Global Positioning System) e a oferta diferencial de água e nutrientes são capazes de manipular a distribuição espacial dos animais (Bailey, 2005). Também em uso já existem balanças automáticas que são instaladas em locais estratégicos, onde os animais são obrigados a passar para terem acesso a, por exemplo, aguadas, e que registram sua identidade, peso e temperatura. Essas informações são interpretadas e mangueiras eletrônicas separam automaticamente aqueles animais que demonstrem alterações suspeitas de tais parâmetros, para posterior tratamento, e enviam por telemetria todas as informações ou as tornam acessíveis pela internet (Hacker et al., 2008). Animais mais fracos podem ser separados automaticamente para potreiros com acesso a suplementação. O sistema também monitora animais que tenham chegado a peso de comercialização.

Com menos sucesso de emprego, as cercas virtuais (Bishop-Hurley et al., 2007) baseadas em tecnologia GPS e WiFi procuram controlar o movimento dos animais de acordo com o interesse maior ou menor de ocupação de certas zonas na pastagem. A necessidade de associação da conseqüência (penalização via descarga elétrica) com estímulos visuais, auditivos ou táteis, tornam complexa a sua aplicação. Os sistemas mais recentes usam freqüências de rádio emitidas do GPS para gerar as fronteiras virtuais (Anderson, 2007). Pedômetros etranspondersestão sendo testados para inferir sobre o estado sanitário e a ocorrência de estro nos animais (Brehme et al., 2008). Por fim, a tecnologia dispõe inúmeras ferramentas de controle dos animais.

Destarte, o monitoramento do comportamento dos animais em pastejo nas escalas individual e de rebanho está na raiz do processo. Mas com qual real intuito?

Para trazer essa discussão, permitam-nos primeiramente contextualizar o argumento. No conjunto da produção agrícola, a agricultura de precisão visa caracterizar a heterogeneidade local (desuniformidade) e buscar sua homogeneização por meio da distribuição variável de insumos no espaço. Em outras palavras, corrigir a variabilidade e padronizar a produção em patamares maximizados. Esse tipo de postura, exclusivamente produtivista da agricultura intensiva, e agora com novas ferramentas georeferenciadas, provou não ter sustentabilidade, principalmente pela perda de biodiversidade, pela poluição oriunda da ineficiência no manejo dos nutrientes, bem como pela fragmentação causada no habitat (Carvalho et al., 2009a). Portanto, a agricultura de precisão não foi concebida para corrigir os erros de origem dos sistemas de produção pós-revolução verde. É provável mesmo que, em curto prazo, os acentue. Não necessariamente no que diz respeito ao manejo dos nutrientes, mas na postergação da premente necessidade de diversidade nos sistemas de produção.

Esta reflexão, trazida aos sistemas pecuários, não é mais otimista. Historicamente a ação antrópica procura "controlar" o pastejo desde o período Neolítico. Desde então, procuramos que os herbívoros domesticados se alimentem daquilo que nós entendemos como aquilo que eles devam se alimentar. De forma geral, desprezando milhares de anos de processos evolutivos que baseiam as relações 
planta-animal, criamos métodos de pastoreio e sistemas de produção que cada vez mais substituem as sábias decisões dos animais por presunçosas, e via de regra incorretas, decisões antrópicas.

Se refletirmos sobre a maioria do que hoje denominamos "tecnologias de produção animal", nada mais são que insucessos humanos na compreensão, e conseqüentemente administração, de ambientes de produção heterogêneos. Exemplos podem ser tomados na substituição de pastagens naturais complexas por monocultivos de gramíneas, homogeneização de rebanhos e especialização do uso de pastagens, lotação rotativa com elevados níveis de insumo em condições de quase ausência de diversidade, sejavegetal ou de herbivoria, etc. Enfim, a lógica não é diferente da aplicada aos sistemas agrícolas. A concepção antrópica está em substituir o complexo, que não entende, pelo simples, que domine. Isto se verifica nas mais diferentes áreas do conhecimento, mas, sobretudo, na agricultura e na pecuária. A conseqüência disso tem sido a baixa sustentabilidade dos sistemas de produção, a poluição ambiental e os diferentes tipos de ameaças sanitárias criadas pelos modelos de produção em voga, dentre outros (Carvalho, 2005).

Segundo Laca (2008), o manejo de pastagens tradicional se baseia em conceitos de equilíbrio, de capacidade de carga anual e homogeneidade espacial. Neste sentido, viria a pecuária de precisão trazer novas ferramentas para uma velha filosofia de uso dos recursos forrageiros? Ou viria para nos auxiliar a compreender e monitorar padrões comportamentais dos animais e interações com a vegetação, integrando a heterogeneidade, os efeitos não lineares, a dinâmica do desequilíbrio dirigida por eventos discretos e efeitos dependentes de escalas espaço-temporais, como sugere Laca (2009b)? Dito isto, acredita-se que a pecuária de precisão esteja numa "encruzilhada filosófica" (Figura 1) e sua aplicação tenha potencial para corrigir os rumos atuais da ciência de manejo das pastagens, ou acentuá-los.

Portanto, se o pastoreio de precisão virá para dar suporte a práticas de manejo de pastagem orientadas para a redução espaço-temporal da heterogeneidade dos recursos forrageiros, enquanto promovendo a perda de biodiversidade, então podemos esperar um decréscimo nos serviços ambientais providos pelos ambientes pastoris. Mas se não obstante aceitarmos o desafio de "manejar a heterogeneidade", usando as novas tecnologias que estão sendo disponibilizadas, então teremos novamente o ambiente pastoril em papel de destaque como provedor de serviços ambientais e mantenedor da biodiversidade.

Da pecuária de precisão ao bocado de precisão

Uma vez que não se possa monitorar ou controlar aquilo que se desconheça, propomos discutir alguns aspectos do processo de pastejo, o qual tem os bocados em sua mínima escala. Portanto, o monitoramento espaço-temporal dos

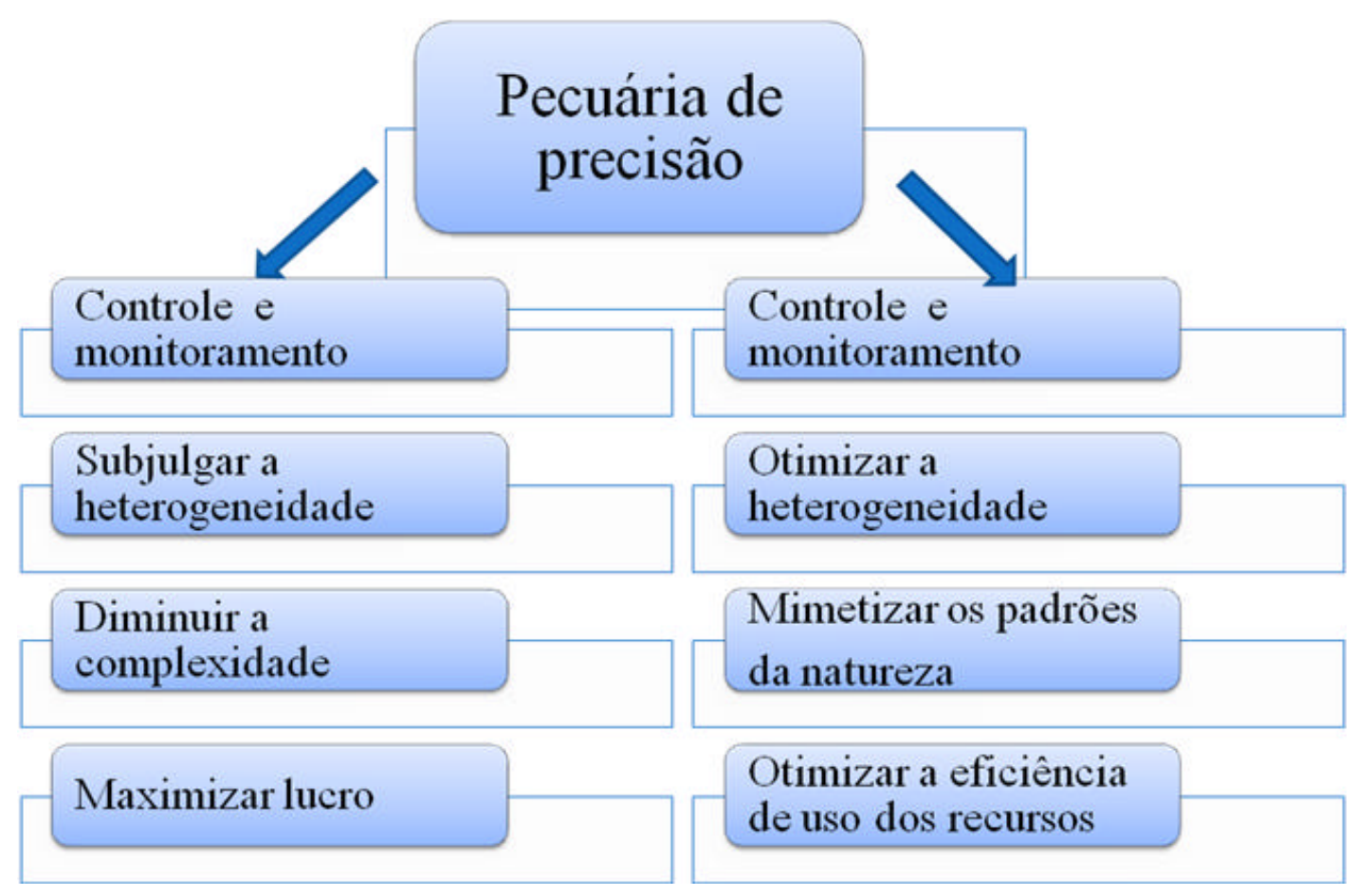

Figura 1 - Dicotomia teórica da aplicação do pastoreio de precisão no manejo das pastagens. 
bocados deve ser visto como fundamental para se atingir as metas do pastoreio de precisão. A lógica está em que a pecuária de precisão, no contexto da produção de ruminantes baseada em pastagens, envolva o monitoramento do processo de pastejo (pastoreio de precisão) o qual, de forma simplista, significa o processo de deslocamento dos animais na busca de alimento, bem como a ação de colheita da forragem pelo bocado e seu processamento para deglutição. Portanto, o pastoreio de precisão, em última análise, finda no monitoramento dos bocados desferidos pelo animal. $\mathrm{O}$ "bocado de precisão" será um termo utilizado no intuito de ressaltar que o bocado, com sua alocação no tempo e no espaço, seja a unidade básica de todo o processo a ser monitorado (Figura 2).

A alocação de bocados no tempo e o espaço é um processo complexo no qual interferimos, atualmente, com poucas ferramentas. Nos sistemas de produção controlamos o pastejo essencialmente pela manipulação da taxa de lotação, do tipo de animal, do método de pastoreio, e da alocação defocina pastagem, tais como aguadas, saleiros, dentre outros. É provável que o pastejo com lotação rotativa seja a forma de manejo onde mais se alcança controlar o bocado, pois define-se com razoável precisão onde e quando os bocados serão desferidos. A despeito desta notável ferramenta de manejo, não se pode dizer que ela supere, por exemplo, o pastoreio com lotação contínua (vide discussão em Briske et al., 2008). Neste último, é possível determinar a intensidade da freqüência de bocados possível de ocorrer num determinado potreiro, mas nada além disso. Ou seja, os bocados são alocados no tempo e no espaço essencialmente por decisões tomadas pelo animal em relação à vegetação a qual interage. Se em lotações adequadas os sistemas de lotação rotativa e contínua são semelhantes, isto equivale a dizer que ainda não compreendemos suficientemente o processo de pastejo a ponto de tirar proveito. Afinal, claro está que não estejamos sendo capazes de suplantar o desempenho dos animais em condições onde eles expressem sua sabedoria em procurar alimento. Esta constatação não permite que sejamos otimistas com relação ao pastoreio de precisão, pelo menos no que se refira ao seu uso no manejo do pastejo, e a julgar pela forma com que issovenha sendo proposto.

Isto nos remete a s eguinte questão: Quais instrumentos estão em uso para monitoramento do animal em nível de bocados? Não se pretende abordar o tema de forma a esgotá-lo. Apenas apresentar alguns instrumentos que mais recentemente, e em maior amplitude, têm sido usados com o intuito de monitorar o pastejo dos animais. Para maiores detalhes a respeito das tecnologias o leitor é referido a Laca \& Wallis De Vries (2000), Ungar \& Rutter (2006), Galli et al. (2006) e Rutter (2007).

Monitorando bocados e o uso dos recursos forrageiros no tempo e no espaço

Penning (2004) descreve um buçal-sensor que se acopla abaixo da mandíbula dos animais e cuja distensão é reconhecida como movimentos mandibulares, armazenandose os registros num tipo dedatalog geracoplado ao animal. Na Figura 3 a pode-se visualizar tal aparato do lado esquerdo do pescoço da vaca. Na Figura $3 \mathrm{~b}$ o mesmo datalogger colocado em um tipo de mochila encilhada nos ovinos.

Os dados armazenados posteriormente são discriminados através de processamento com o software Graze (Rutter, 2000). Esses tipos de registros já foram

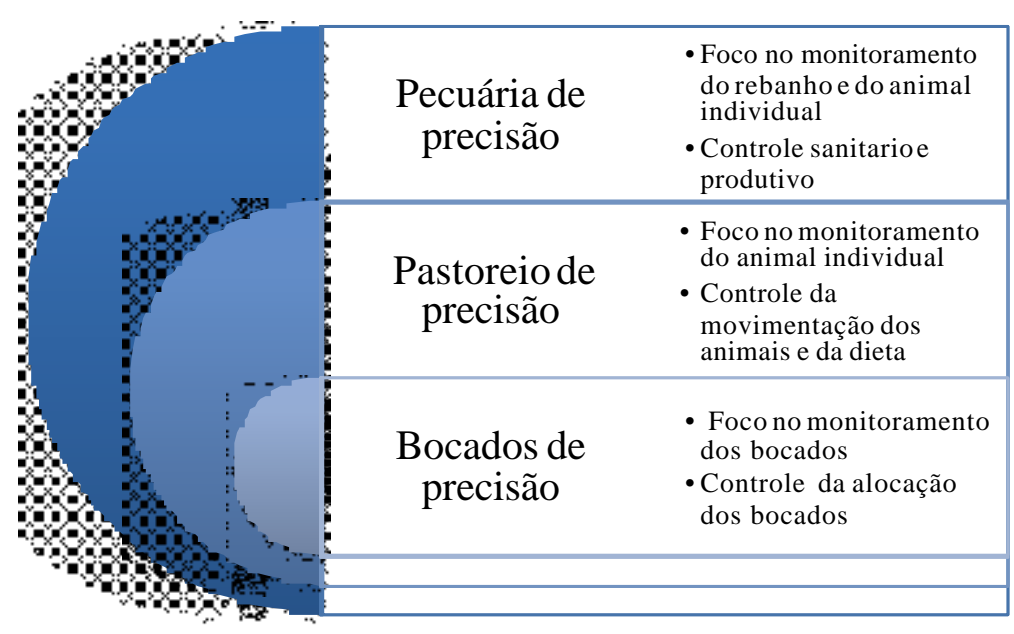

Figura 2. Sobreposição de enfoques e objetivos da pecuária, do pastoreio e dos bocados de precisão. 
realizados em protocolos conduzidos no Brasil em diferentes espécies animais (ovinos e bovinos de corte e de leite) e em pastagens naturais e cultivadas (Gonçalves et al., 2009a; Gonçalves et al., 2009b; Amaral, 2009). Os movimentos mandibulares podem ser identificados e classificados como bocados e não-bocados de acordo os critérios de amplitude e frequiência especificados pelo usuário (Ungar \& Rutter, 2006). Os registros podem ser observados na escala de segundos e ainda são capazes de fornecer o tempo em pastejo, ruminação e outras atividades, dentre outras informações.

Outra forma de monitorar o comportamento ingestivo é o monitoramento acústico, já proposto por um considerável número de publicações (Laca \& Wallis De Vries, 2000; Ungar \& Rutter, 2006; Galli et al., 2006). A bioacústica é uma técnica relativamente barata e nãoinvasiva, comparativamente as demais técnicas automatizadas. O princípio está em que os movimentos mandibulares têm características acústicas que permitem sua distinção como bocados, mastigação e movimentos compostos de mastigação-bocado, e a intensidade e tipo das ondas sonoras produzidas pelo pastejo estariam associadas com a quantidade de forragem ingerida (Laca \& Wallis De Vries, 2000). Com base nesta hipótese, registros sonoros estão sendo realizados em protocolos que avaliam de forma concomitante a ingestão de forragem (Figura 3).

As fotos apresentam animais equipados com gravadores e microfones posicionados na fronte (vaca) ou na porção distal da maxila (ovinos) em diferentes protocolos experimentais com o intuito de captar os sons produzidos durante a alimentação. Ungar \& Rutter (2006) compararam a técnica bioacústica com o IGER Behaviour Recorder e concluíram por uma razoável correspondência entre procedimentos, no que diz respeito à classificação dos movimentos mandibulares. Segundo $\mathrm{Gibb}^{3}$, há evidências de que esta técnica possa predizer também o tipo de espécie vegetal ingerida pelo animal, bem como a sua digestibilidade.
Por essas razões é considerada, por Gibb, como a novidade técnica que representa o maior avanço dentre as metodologias para descrever a dinâmica dos movimentos mandibulares e estimar consumo.

Além disso, há possibilidades de que se possa predizer em qual tipo de estrutura no pasto os animais estariam alocando bocados. Em protocolo recente, Trindade et al. 2008 (dados não publicados) gravaram registros de som produzidos por animais que se alimentavam em pastos com alturas contrastantes (Figura 4).

As saídas dos registros podem ser visualizadas em softwares de áudio, onde cada pico representa o som produzido durante o movimento mandibular. Percebe-se um padrão diferenciado de registros, onde os movimentos mandibulares em pastos altos demonstram ter maior duração e estão associados com movimentos de mastigação (picos menores) antes do corte da forragem (picos maiores), movimentos esses considerados compostos e típicos de situação de bocados de elevada massa. Já em pastos baixos os movimentos parecem ser predominantemente excludentes, típicos de baixa massa de bocado. O software para suporte à interpretação dos registros sonoros ainda está em desenvolvimento (Milone et al., 2009), mas a aplicação deste método para a avaliação da ingestão de forragem significa um avanço em relação a outros métodos de monitoramento animal (Carvalho et al., 2007).

Procurando ilustrar o emprego dessas tecnologias no monitoramento do deslocamento animal e da dinâmica dos bocados, se apresentam alguns exemplos de mapeamento da vegetação combinado com informações de comportamento ingestivo dos animais. Para os objetivos desta ilustração, tomemos umexperimento em pastejo de longa duração em campo natural. Primeiramente, SIG e GPS foram usados para mapear a vegetação, identificando súios e caracterizando estruturas de pasto. Então, o comportamento ingestivo e o deslocamento dos animais são monitorados de forma concomitante por GPS, IGER
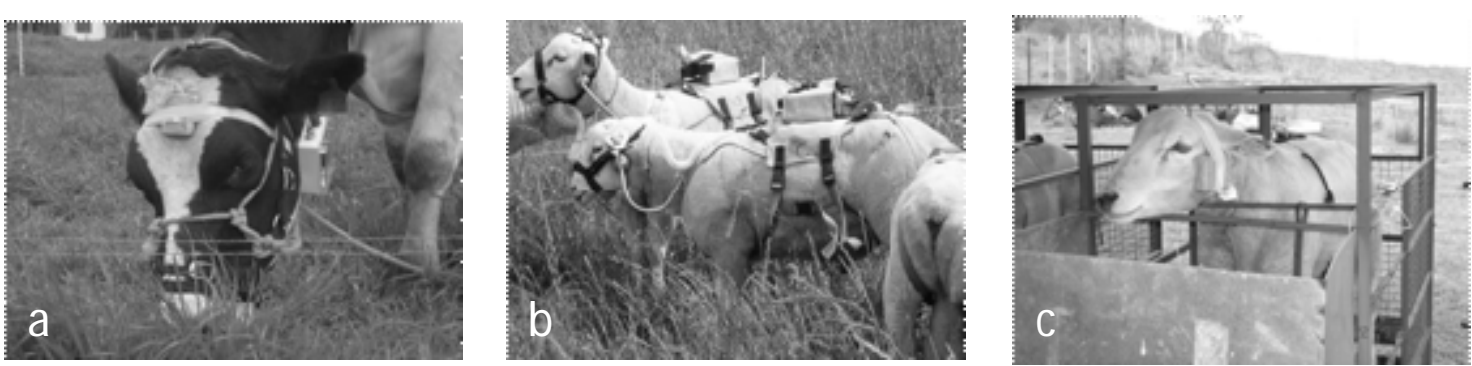

Figura 3. Bovinos (a) e ovinos (b) equipados com registradores de movimentos mandibulares (IGER Behaviour Recorder) e gravadores com microfones localizados na fronte (bovino) ou na porção distal da maxila (ovinos). Borrego (c) em gaiola metabólica visando relacionar o consumo com a acústica registrada durante sua alimentação (GPEP-UFRGS, Fotos: Julio K. da Trindade). 


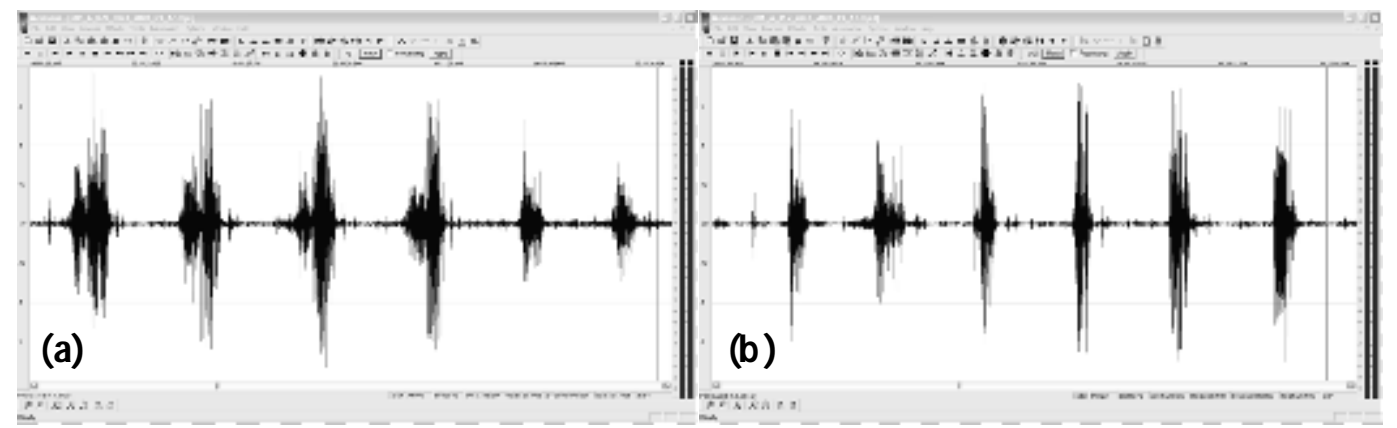

Figura 4 - Registros acústicos em vacas leiteiras durante a atividade de pastejo. Os picos representam bocados e/ou outros movimentos mandibulares no pastejo de azevém anual com alturas de $32 \mathrm{~cm}$ (a) e $6 \mathrm{~cm}$ (b) (Trindade et al., dados não publicados).
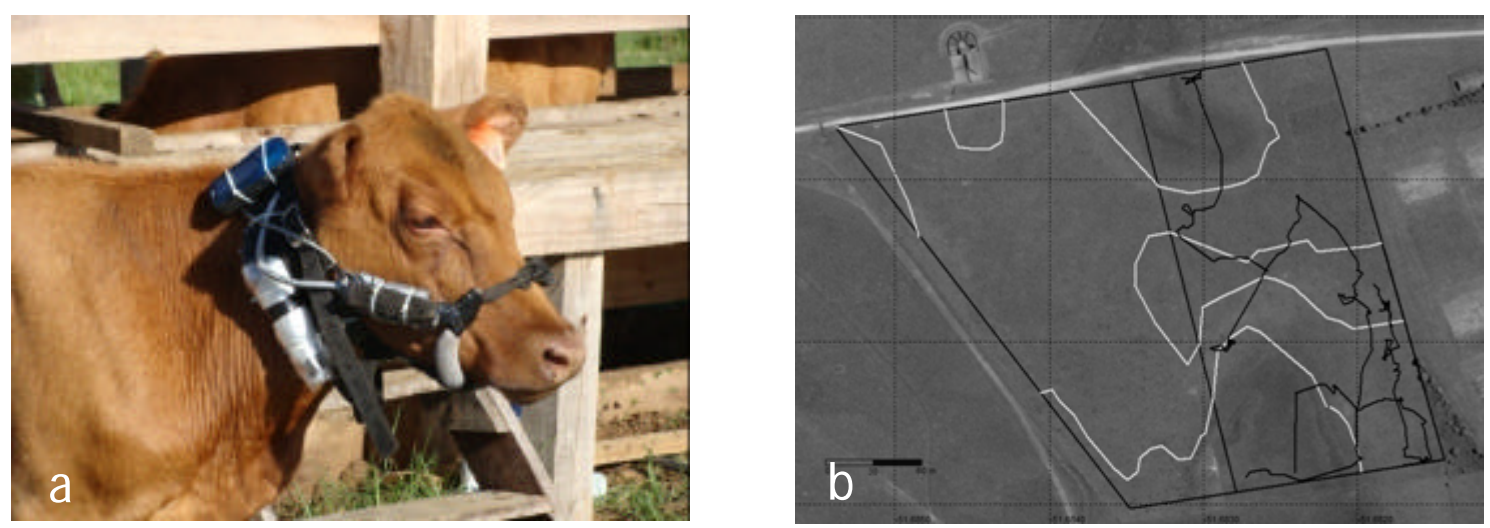

Figura 5 - Novilha com IGER Behaviour Recorder, gravador com microfone e GPS (a). Na imagem (b) encontra-se a integralização das informações obtidas pelos equipamentos. A linha preta descontínua apresenta a trajetória em atividade de pastejo. As linhas claras delimitam sítios de pastejo, enquanto a linha preta retilínea define os limites do piquete. (UFRGS, Fotos e imagem: Cassiano E. Pinto).

Behaviour Recorder e bioacústica para representar os locais de forrageamento (Figura 5).

Enquanto o IGER Behaviour Recorder e o microfone registram as atividades de pastejo, o GPS registra todo o trajeto dos animais. A partir do cruzamento dos controles de forma concomitante no tempo, é possível separar a parte do trajeto que se constitui efetivamente em atividade de pastejo. Esta informação, sobreposta ao mapeamento da vegetação, informa quais locais do piquete, e quais estruturas de pasto, estão sendo mais visitados pelos animais. No que concerne a precisão e acurácia do GPS para esses tipos de estudo, o leitor é referido a Rutter (2007).

O monitoramento conjunto das diferentes atividades (pastejo, ruminação, descanso, entre outros) e de sua posição por GPS pode se tornar uma ferramenta decisiva na identificação dos componentes preferidos da dieta. Com essa informação prévia poder-se-ia identificar e delimitar áreas de preferência, bem como promover o aumento dos componentes preferidos ou do valor percebido de um determinado sítio. Isto permitiria progressos que, num curto prazo, aportariam subsídios para inferências mais precisas acerca do manejo da lotação e da utilização sustentável das pastagens. Assim, as ferramentas de monitoramento animal podem ser importantes para definir que espécies animais e categorias podem ser utilizadas, assim como melhor definir a disposição espacial de aguadas, saleiros, comedouros e outros foci, com o objetivo de melhorar o uso dos recursos disponíveis e promover visitas aos locais poucos frequientados na pastagem (Laca, 2008).

Em exemplo com outro protocolo de longa duração, o GPS é utilizado para o mapeamento de áreas de pastagens submetidas a diferentes intensidades de pastejo. Utilizouse um penetrômetro eletrônico PenetroLOG, marca Falker, modelo PLG1020, acoplado a um sistema automatizado SoloStar ejunto a um quadriciclo, com DGPS Recon, marca Trible, para o registro das coordenadas do ponto amostrado. 


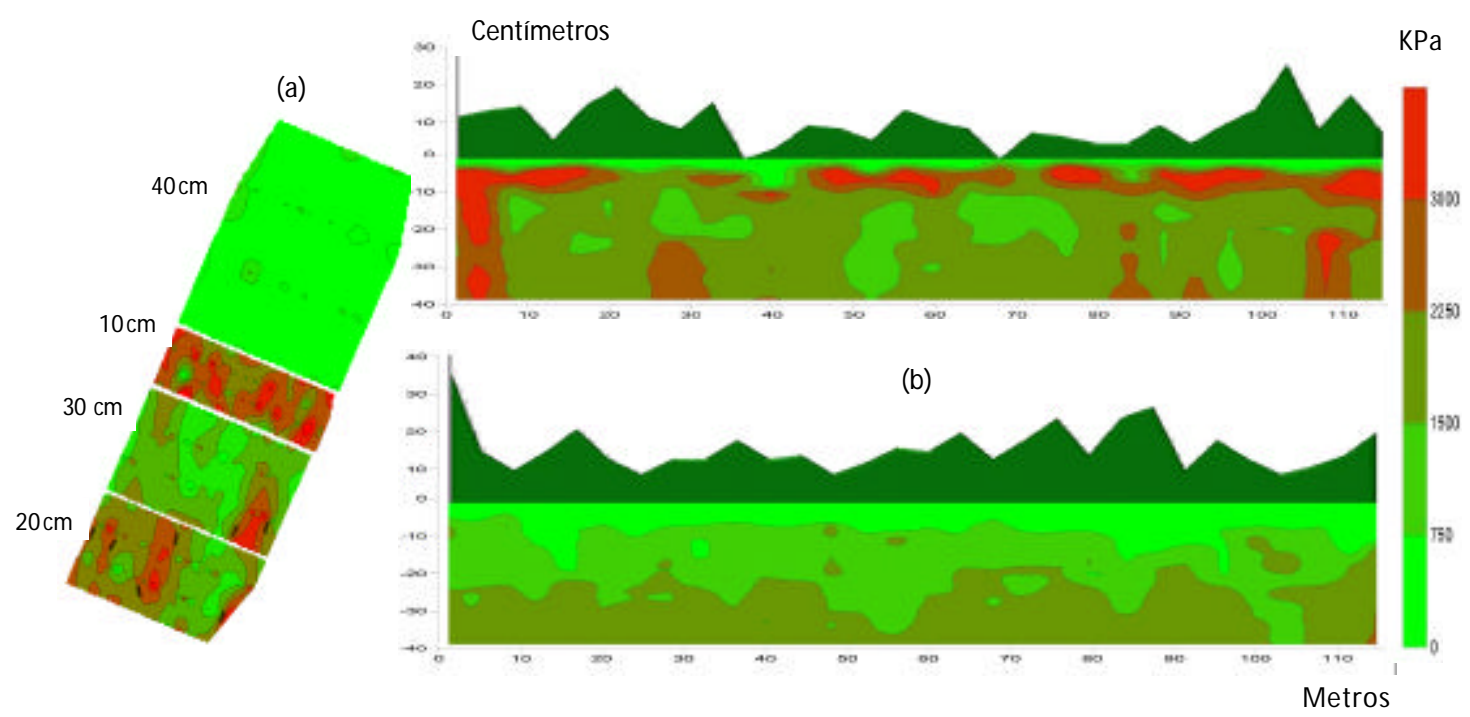

Figura 6 - Imagens georeferenciadas de resistência a penetração na camada de solo de 0-10 cm em quatro piquetes segundo alturas de manejo do pasto (a) e de resistência a penetração e altura do pasto ao longo de uma transecta (b) em piquetes manejados a 10 (acima) e $40 \mathrm{~cm}$ de altura (abaixo). Escala de resistência a direita em KPa (Machado et al. 2008, dados não publicados).

O equipamento possui uma haste com ponta padronizada pela Asae (tipo 2) e base refletora para calcular a profundidade das leituras. O impacto georefenciado do pastejo é oportunizado pela técnica, e mapas de resistência a penetração são gerados ao se obter, de forma concomitante, medidas de penetrômetro, de altura do pasto, e seus posicionamentos no espaço (Figura 6).

Como se pode observar, ao final de oito anos de aplicação dos tratamentos as maiores intensidades de pastejo apresentam áreas com elevados níveis de resistência a penetração. Os piquetes manejados com 10 e $40 \mathrm{~cm}$ de altura apresentam-se relativamente homogêneos quanto ao impacto espacial do pastejo medido por esta variável. Já os tratamentos $30 \mathrm{~cm}$, e principalmente o manejo com $20 \mathrm{~cm}$ de altura, promovem a ocorrência de áreas bastante contrastantes em termos de resistência do solo a penetração (Machado et al., dados não publicados). Empiricamente, é possível verificar que há uma correspondência entre a altura do pasto e a resistência do solo a penetração (Figura 6b), havendo maior ocorrência de áreas com maior resistência a penetração sob áreas de pastos com menor altura. Este tipo de ferramenta permite identificar os sítios com maior freqüência de visitas no piquete, bem como aqueles mais recusados. No que diz respeito a áreas integradas com agricultura, o manejo de forma a distribuir melhor o pastejo e reduzir o impacto do pisoteio no espaço é importante na redução dos riscos para a lavoura em sucessão (Carvalho et al., 2009).

Para concluir, no ambiente pastoril vários são os padrões de comportamento ingestivo que podem ser apresentados pelos animais em pastejo, cabendo ao manejador do sistema interpretá-los para se obter eficiências nas repostas de interesse. Para tanto, os estudos de comportamento ingestivo e de memória espacial dos animais são importantes para conhecer os processos de identificação e de preferências aos recursos disponíveis. Com base nesta informação, é possível delimitar locais ou ambientes a serem utilizados pelos animais, e equilibrá-los em função das suas necessidades, atuando com condicionamentos clássicos ou instrumentais, e mesmo treinamentos por aversão e recompensa (Edwards et al., 2008).

Essa nova maneira de propor estratégias de manejo nada mais é do que aprender com os animais, ao invés de ensiná-los, pois se as bases evolutivas das relações plantaanimal estão corretas, a racionalidade das decisões dos animais deve ser levada em conta no manejo da pastagem (Carvalho et al., 2006). Ainda no caso da pecuária, o conhecimento dos padrões de comportamento animal é fundamental para o desenvolvimento de métodos integrados com tecnologia eletrônica sem fio e sistemas de decisão para o manejo de animais em pastejo, o qual define a pecuária de precisão. Segundo Laca (2008), grande parte do sucesso da pecuária de precisão depende de um profundo conhecimento do comportamento animal.

Ruminantes engenheiros construindo ambientes pastoris com bocados de precisão

Para ilustrar como podemos gerenciar ambientes pastoris com bocados de precisão, comecemos com alguns resultados do mesmo protocolo experimental de longo prazo, com intensidades de pastejo sendo aplicadas em pastagem 
natural, conforme previamente apresentado. É importante que se diga tratar de uma comunidade complexa do ponto de vista florístico e estrutural, e que o ajuste da carga animal, para efeito deste exemplo, é o meio de ajustar o bocado no conceito do pastoreio de precisão.

Consideremos que, por meio da diminuição da oferta de forragem, aumenta-se a probabilidade de ocorrer um bocado em determinando momento e local da pastagem. Este bocado, numa comunidade vegetal complexa, tem a possibilidade de encontrar os mais diferentes tipos funcionais, com os mais diferentes ritmos morfogênicos (Cruz et al., 2009). Enfoquemos inicialmente duas das principais espécies indicadoras da pastagem em questão. Primeiramente o Paspalum notatum, pois a sua maior ou menor presença representa a existência de fisionomias mais homogêneas $(+P$. notatum $=$ pastagem com um único estrato inferior) ou mais heterogêneas $(-P$. notatum $=$ pastagem com duplo estrato e formação de touceiras). Em segundo o Andropogon lateralis, espécie de elevada plasticidade e principal formadora de touceiras na vegetação em questão.

Transformando o filocrono de P. notatume A.lateralis de tempo térmico em número de dias entre a formação de duas folhas sucessivas, observa-se na Figura 7 o número de dias correspondentes a este intervalo ao longo das estações de crescimento de primavera e verão.

A partir do padrão de emissão de folhas dessas espécies, consideremos o padrão de ocupação de estações alimentares pelos animais em função da oferta de forragem (Mezzalira, 2009). Se assumirmos a estimativa desta freqüência de visitas como indicador da freqüência de alocação dos bocados numa mesma área, observamos o impacto potencial das diferentes intensidades de pastejo sobre as espécies em questão. A lógica é que imprimindo uma freqüência maior ou menor de bocados por meio de, no caso, ajustes na carga animal, essa freqüência possa mais se adaptar a um ou outro ritmo morfogênico. Esse sincronismo entre planta e animal significaria a busca pela similaridade entre o período de retorno ao perfilho pastejado e a taxa de emissão de folhas, possibilitando que a planta se regenere antes de ser pastejada por duas vezes consecutivas, ao mesmo tempo em que o animal encontre disponibilidade de folhas e possibilidade de seleção no decorrer do pastejo.

O padrão de ocupação de estações alimentares de novilhas sob lotação contínua com baixa oferta diária de forragem (4 $\mathrm{kg}$ de $\mathrm{MS} / 100 \mathrm{~kg}$ de peso vivo) resulta que o intervalo estimado entre duas desfolhas sucessivas seja inferior a seis dias (Mezzalira et al., 2008). A fisionomia resultante é a de um pasto rapado, com tipologia funcional predominante por espécies com baixo teor de MS e elevada área foliar específica (Cruz et al., 2009). Já a intensidade de pastejo de moderada (12 kg de MS/100 kg de peso vivo) se molda ao ritmo morfogênico do $\mathrm{P}$. notatum e aumenta significativamente a probabilidade do A. lateralis conseguir emitir folhas em locais na pastagem com menor freqüência de visitas. Isto gera uma pastagem com estrato inferior predominando $P$. notatum com altura relativamente elevada, e ocorrência controlada de touceiras de A. lateralis em zonas menos visitadas. Este tipo de estrutura vem produzindo os melhores resultados de desempenho animal há 21 anos (Carvalho et al., 2008).

Já a baixa intensidade de pastejo (16 kg de MS/ $100 \mathrm{~kg}$ de peso vivo) significaria um ritmo de desfolha bastante inferior ao da produção de folhas de P. notatum, favorecendo espécies com características de crescimento lento e elevada duração de vida da folha (Carvalho et al.,

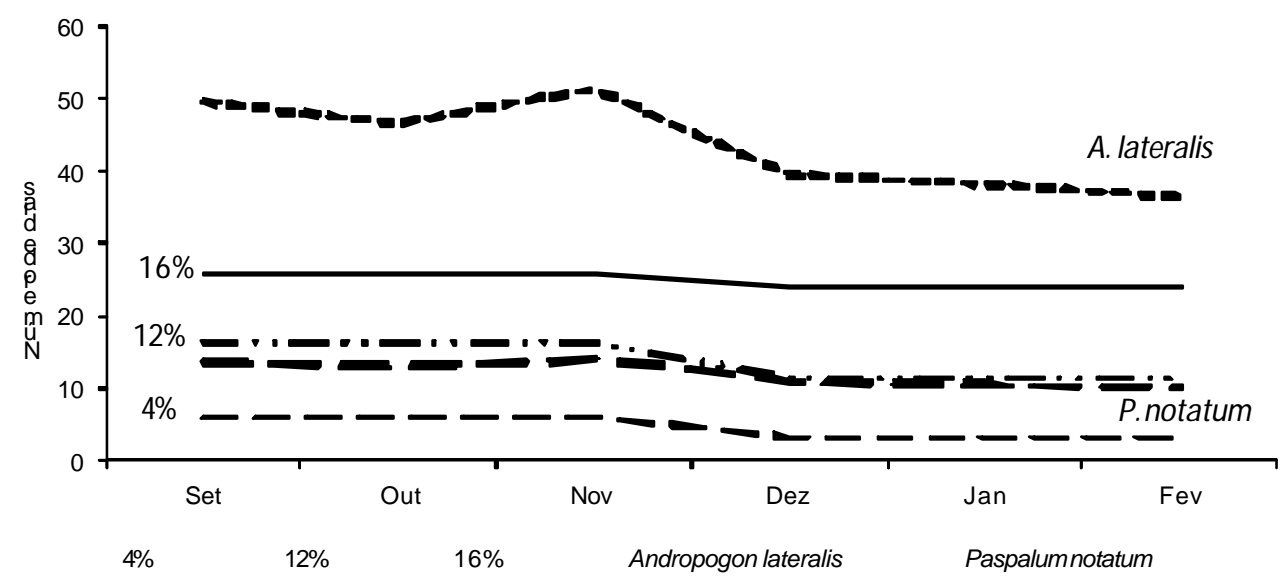

Figura 7 - Estimativa do número de dias entre a formação de duas folhas sucessivas de Paspalum notatum e Andropogon lateralis e do número de dias para o retorno do pastejo numa mesma estação alimentar segundo ofertas de forragem de 4,12 ou $16 \%$ (em $\mathrm{kg}$ de MS/100 kg de peso vivo). Adaptado de Mezzalira et al. (2008). 
2007). Na medida em que a ocorrência de desfolha diminua, a comunidade passa a ter sua dinâmica predominantemente gerenciada pela competição por luz, quando A. lateralis adquire sucesso em sua forma de touceira. Neste exemplo, pode-se verificar que o controle da intensidade de pastejo possa construir uma vegetação com maior ou menor proporção de touceiras, que por sua vez se traduz em pastos com maior ou menor diversidade (Soares et al., 2003).

$\mathrm{O}$ incremento na freqüência de touceiras na medida em que se aumenta a oferta de forragem pode ser observada na Figura 8.

Os resultados apresentam também o padrão de ocupação de estações alimentares e a concomitante freqüência de touceiras. Mezzalira (2009) observou que, inicialmente, o número de estações alimentares visitadas é similar ao número de estações potencias quando em situação de baixa oferta de forragem. Em tais condições, praticamente inexistem estações rejeitadas durante o pastejo e, portanto, a seletividade é praticamente igual a zero. Com o aumento da oferta de forragem, o número de estações alimentares visitadas decresce em relação ao número de estações potencialmente disponíveis (aumento da seletividade). A diferença entre o número de estações visitadas e o número de estações alimentares potenciais reflete o processo de seleção e escolha das melhores estações alimentares (Mezzalira, 2009). Notase um incremento neste processo (área entre as duas linhas decrescentes) até a oferta de $10 \%$, momento este que os pastos atingem $6 \mathrm{~cm}$ de altura e as touceiras ultrapassam a freqüência de $30 \%$. A partir de então, ocorre uma inversão no processo (até seletividade $=0$ em $14 \%$ de oferta) e a partir de $14 \%$ ocorre ocupação de maior número de estações que a média disponível, com a freqüência de touceiras atingindo valores próximos a 50\% (Mezzalira, 2009).
Carvalho et al. (2009b) demonstram que não somente a freqüência das touceiras é influenciada pela intensidade de pastejo, mas também sua estrutura espacial. A distância média entre touceiras diminui, e a circunferência média ocupada pelas mesmas aumenta, quanto maior a massa de forragem do estrato inferior (o que ocorre nas maiores ofertas de forragem). Os autores verificaram uma correlação positiva entre altura das touceiras e a altura do estrato inferior. Na maior altura do estrato inferior observou-se que mais de $80 \%$ das touceiras apresentavam-se com pouco ou nenhum grau de desfolha, enquanto que na menor altura em torno de $50 \%$ das touceiras apresentavam grau de desfolha intermediário.

Como mencionado por Derner et al. (2009), variações na estrutura da vegetação podem não ocorrer em escalas espaço-temporais apropriadas para objetivos conservacionistas. Os dados de Mezzalira et al. (2008) e Mezzalira (2009) ilustram como nós podemos influenciar a fisionomia da vegetação pela determinação das freqüências potenciais de bocados num determinado sítio, no intuito de criar estruturas com diferentes frequiências e distribuições de estratos inferiores e superiores. Para tomar apenas uma ilustração, a quantidade e a diversidade de aves são influenciadas pela heterogeneidade (Derner et al., 2009), sendo menos abundantes quando a intensidade de pastejo reduz a variabilidade na estrutura da vegetação (Batáry et al., 2007). Portanto, pela manipulação indireta da freqüência de ocorrência de bocados nos sítios de pastejo podemos criar estruturas para diferentes tipos e quantidades de aves. Este exemplo simplista demonstra como podemos impactar a qualidade do ambiente pastoril pelo manejo dos animais. Esta mesma lógica pode ser esperada em relação a muitos outros serviços ecossistêmicos. Por conseguinte, o ambiente

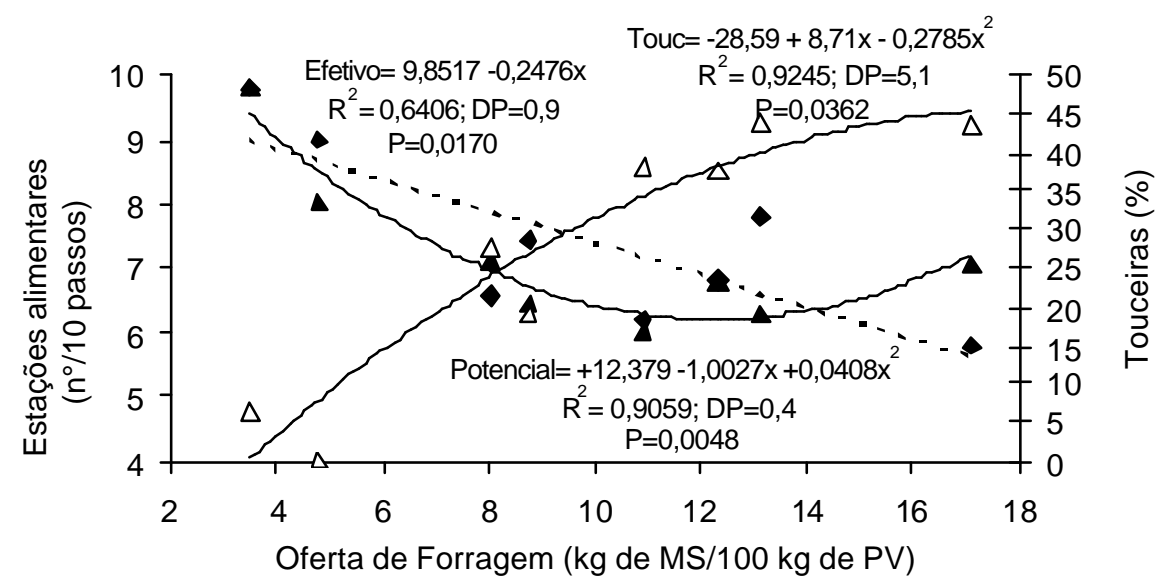

Figura 8 - Porcentagem de touceiras $(\Delta)$, taxa de encontro efetivo ( $\Delta$ ) e taxa de encontro potencial $(\bullet)$ de novilhas em pastagem nativa manejada sob ofertas de forragem (Mezzalira, 2009). 
pastoril é algo que deva ser construído e conservado. No que diz respeito a construção de estruturas de vegetação, o manejo do pastejo é, sem dúvida, um elemento crucial no sistema.

\section{Construindo estruturas de pastos para alocar bocados de precisão}

Vários estudos confirmam a importância da altura do pasto na determinação das dimensões do bocado, em particular sua influência sobre a profundidade do bocado (Wade, 1986, Carvalho, 1987, Laca et al., 1992, Hodgson et al. 1994, Dittrich et al., 2008, Gonçalves et al., 2009b). Em outras palavras, a estrutura do pasto afeta a ingestão desde o seu menor nível de resolução, o bocado. Carvalho et al. (2008) têm argumentado que o manejo de pastagens deva significar a criação de estruturas que otimizem as relações planta-animal desenvolvidas há milhares de anos. Neste sentido, a construção de estruturas de pasto para alocação precisa de bocados pode ser vista como uma das aplicações do pastoreio de precisão, na medida em que signifique metas de estrutura que devam ser precisamente moldadas pelos bocados. Esse conceito será exemplificado por meio de protocolos que envolvem pastoreio com lotação rotativa e controle de estruturas de entrada e de saída dos animais.

Amaral (2009) investigou o processo de ingestão de vacas leiteiras ao longo do rebaixamento de pastos de azevém anual sob combinações de duas alturas pré-pastejo $(15$ e $25 \mathrm{~cm})$ e duas alturas pós-pastejo $(5 \mathrm{e} 10 \mathrm{~cm})$. Consideremos que, para o contexto do pastoreio de precisão, a definição de uma camada a ser extraída do pasto, ao longo de um período de ocupação, seja o equivalente a alocação precisa de bocados no espaço. E que após a saída dos animais, o período de descanso seja o equivalente a definição de uma escala temporal entre bocados. A maneira como o animal pasteja durante o período de ocupação é função da estrutura definida para a entrada e a saída dos animais, ou em outras palavras, do estrato do dossel a ser extraído (Figura 9).

No início do período de ocupação, os animais encontram maior proporção de material preferencialmente removível (folhas). Com a redução da altura do pasto (mais que $40 \%$ da altura inicial), a taxa de remoção diminui devido à menor quantidade de material preferido e aumento da presença de colmos e bainhas no horizonte de pastejo, estruturas essas limitantes da profundidade do bocado (Carvalho et al., 2008). Em outras palavras, a redução significativa da taxa de rebaixamento indica que o animal pasteja uma segunda camada da estrutura oferecida, onde a redução da taxa equivale à perda de interesse do animal no pastejo.

Em experimento análogo, Trindade et al. (2009) reportaram que estruturas com elevada altura de entrada, que signifiquem a presença de colmos em posições elevadas do dossel, dificulta o alcance de metas de estrutura para o pós-pastejo, pois os animais se recusam a pastejar a partir de "uma certa estrutura". Pastos de braquiária, cujo ponto de entrada se defina por quando o dossel atinja $95 \%$ de interceptação luminosa, apresentam maior proporção de folhas no dossel a ser rebaixado. A exemplo do constatado por Amaral (2009), os autores observaram elevada taxa de

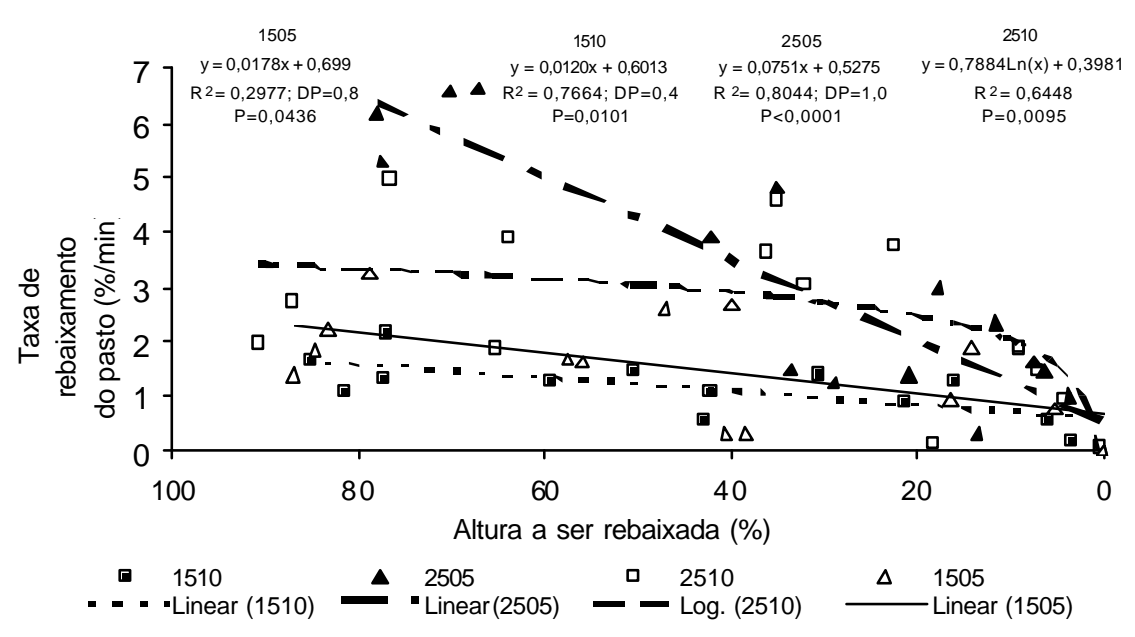

Figura 9 - Taxa de rebaixamento do pasto (\%/minuto) em função da altura a ser rebaixada ao longo do período de ocupação de uma pastagem

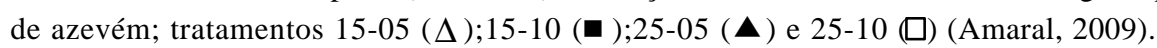


rebaixamento no início do pastejo, que diminui acentuadamente até os $40-50 \%$ da altura a ser rebaixada, a partir do qual a taxa se mantém mais ou menos constante até o final do rebaixamento.

Os resultados acima sugerem como os animais interpretam as modificações da estrutura. No caso de perfis de pasto oferecidos em pastejo com lotação rotativa, ao longo do período de ocupação ocorrem modificações significativas na abundância e proporção dos diferentes componentes morfológicos. A estrutura e a forma como a forragem é oferecida ao animal se modificam de forma rápida e incomparável a uma situação de lotação contínua, e obviamente dependem das estruturas pré e pós-pastejo definidas como meta (Figura 10).

Ainda com relação a estrutura de entrada, embora haja uma relação direta e positiva entre a altura e a massa do bocado pelo impacto que a profundidade do bocado tem sobre as dimensões do bocado, há uma altura ótima a se ter como meta. Ainda que se possam ter incrementos de massas do bocado em alturas muito elevadas, o aumento no custo temporal em realizá-lo acaba por penalizar a taxa de ingestão (Carvalho et al., 2001b; Silva et al., 2007; Gonçalves et al., 2009b). Isto ocorre porque o tempo para formação do bocado aumenta em virtude da necessidade, cada vez maior, de movimentos manipulativos que os animais são obrigados a realizar, no intuito de trazerem a forragem dispersa no espaço até o momento da deglutição (Carvalho et al., 2001a).

No caso das alturas de saída, é comum que a estratégia de manejo em lotação rotativa priorize a eficiência de colheita de forragemo que, em última análise, significa estruturas de pós-pastejo baixas e com pouca ou quase nenhuma folha. Nessas condições, onde se force o animal a pastejar estratos com predominância de colmos e de material senescente, é comum que se observem aumento nos intervalos intrarefeição (Amaral, 2009), diminuição do tempo em alimentação (Ribeiro Filho, 2003) e diminuição da taxa de bocados (Trindade et al., 2009). Portanto, tão importante quanto o ponto de entrada é o momento de saída dos animais na rotação.

A complexidade das alturas de entrada e de saída, aqui apresentadas dentro do contexto da pecuária de precisão, não envolve a resposta do pasto e a dinâmica da interceptação luminosa e da dinâmica populacional de perfilhos da pastagem, o que tornaria ainda mais complexa a discussão. De forma simplista, as estruturas de entrada enfocando ambos o animal (consumo) e o pasto (crescimento) têm convergido para estruturas ótimas similares (Silva \& Carvalho, 2005). Não obstante, a estrutura de saída ainda está muito pouco trabalhada.

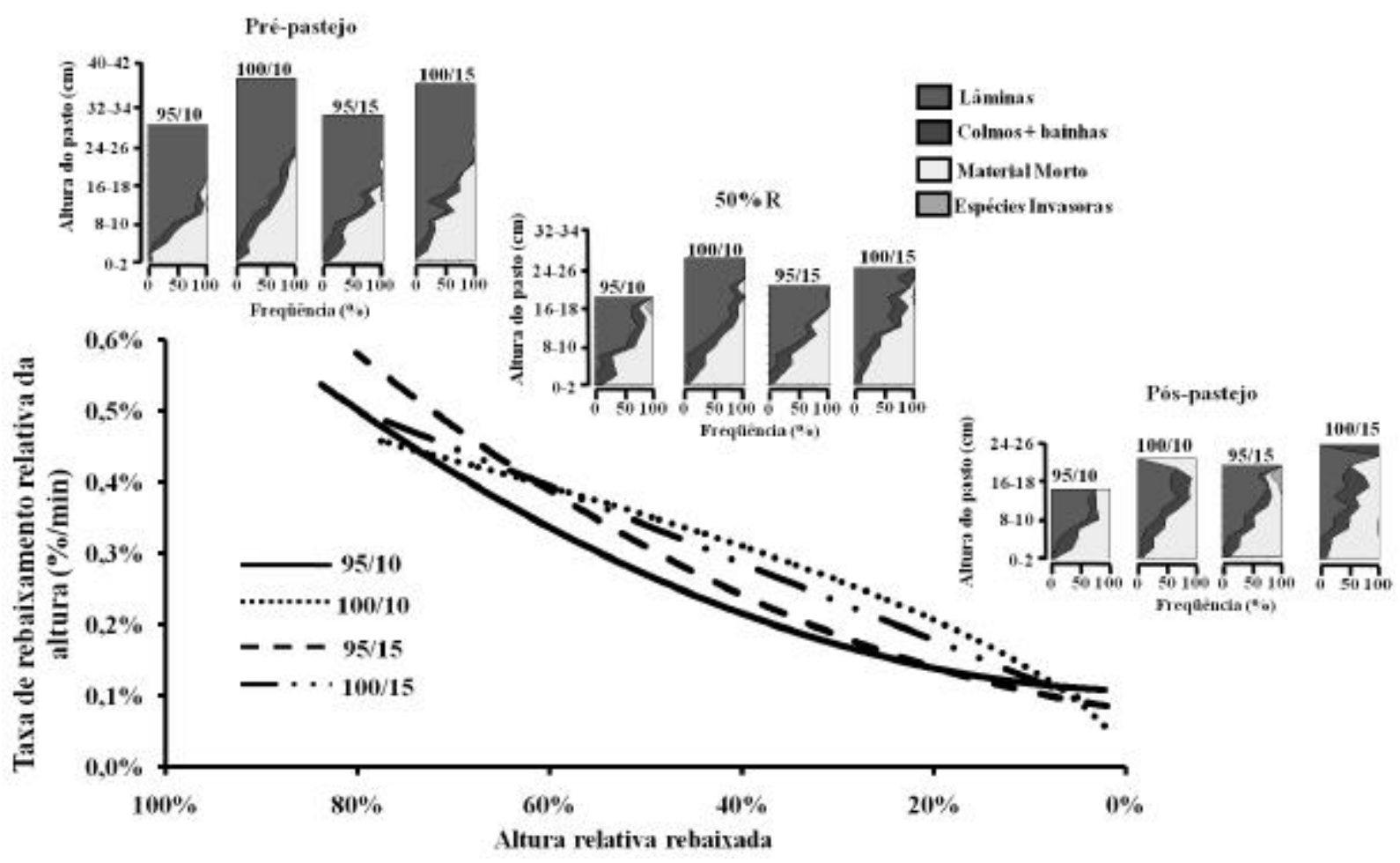

Figura 10 - Taxa de rebaixamento do pasto (\%/minuto) e composição morfológica da estrutura do pasto em função da altura a ser rebaixada ao longo do período de ocupação de uma pastagem de capim Marandú. Os tratamentos referem-se a estruturas de entrada e de saída controladas por níveis de interceptação luminosa e alturas do pasto, respectivamente. (Modificado de Trindade et al., 2009). 
Os impactos da altura de entrada e de saída nesses exemplos ilustram a importância dos conceitos de “construção de estruturas de pasto" e da "alocação espaçotemporal dos bocados" na gestão dos ambientes pastoris. O enfoque da pecuária de precisão, nesse contexto, pode assumir inúmeras aplicações. Importante é concluir que quanto mais assumirmos a responsabilidade de "determinar" quando e onde quais tecidos vegetais serão colhidos pelos animais, maiores os custos de eventuais erros no manejo dos ambientes pastoris. Estamos preparados para tal responsabilidade?

\section{Considerações finais}

Informações sobre o comportamento animal e sua localização podem ser utilizadas para delimitar locais ou ambientes a serem utilizados pelos animais, e equilibrá-los em função de suas necessidades. Para tanto, a pecuária de precisão necessita considerar a dinâmica do processo de pastejo em sua escala mínima, o bocado. Uma vez que o papel dos herbívoros domésticos não seja mais a simples colheita de tecidos vegetais e sua conversão em produto animal, pois a eles são exigidos compromissos com serviços ecossistêmicos, origina-se o papel do ruminante como engenheiro ambiental. Esta multi-funcionalidade, requerida para as pastagens, postula novos paradigmas e ferramentas para responder aos recentes questionamentos desta sociedade em transformação. Eis o potencial da pecuária de precisão. Finalizamos afirmando que este trabalho não teve a pretensão de tratar o assunto de forma extensiva, mas sim estimular a reflexão de como tem sido conduzida a ciência do pastejo até o momento, e como pode vir a ser a partir das ferramentas tecnológicas que começam a estar a nossa disposição. Tememos que a pecuária de precisão se transforme em nova ferramenta para um velho e mau hábito antrópico, o de controlar para restringir, o de simplificar para não precisar entender, enfim, o de desconsiderar a necessidade de mimetizar padrões e processos naturais nos sistemas de produção. Por outro lado, acreditamos estar em face de ferramentas e oportunidades sem precedentes para aprender com os animais e poder otimizar processos capitais da interface planta-animal. Cabe a nós decidir por qual caminho iremos trilhar.

\section{Agradecimentos}

A Carolina Bremm, Davi Teixeira dos Santos, Lidiane Fonseca e Reuben Mark Sulc pelos aportes e melhorias ao texto, bem como ao CNPq pelas bolsas e ao Projeto CAPES/ SPU - CAPG/BA 036/07.

\section{Literatura Citada}

AMARAL, M.F. Estrutura do pasto como determinante do consumo de matéria seca por vacas leiteiras em diferentes tipos de pastagens. 2009. Dissertação (Zootecnia) - Universidade Federal do Rio Grande do Sul. 2009 (submetida).

ANDERSON, D.M. Virtual fencing - past, present and future. The Rangeland Journal, v.29, p.65-78, 2007.

BATÁRY, P.; BÁLDI, A.; ERDDS, S. Grassland versus non-grassland bird abundance and diversity in managed grasslands: local, landscape and regional scale effects. Biodiversity Conservation, v.16, p.871-881, 2007.

BAILEY, D.W. Identification and creation of optimum habitat conditions for livestock. Rangeland Ecology and Management, v.58, p.109-118, 2005.

BISHOP-HURLEY, G.J.; SWAIN, D.L.; ANDERSON, D.M. Virtual fencing applications: Implementing and testing an automated cattle control system. Computers and Electronics in Agriculture, v.56, p.14-22, 2007.

BREHME, U.; STOLLBERG, U.; HOLZ, R. et al. ALT pedometer New sensor-aided measurement system for improvement in oestrus detection. Computers and Eletronics in Agriculture, v.62, p.73-80, 2008.

BRISKE, D.D.; DERNER, J.D.; BROWN JR. et al. Rotational grazing on rangelands: reconciliation of perception and experimental evidence. Rangeland Ecology and Management, v.61, p.317, 2008.

CARVALHO, P.C.F. Relações entre a estrutura da pastagem e o processo de pastejo com ovinos. 1997. 150f. Tese (Doutorado) - Universidade Estadual de São Paulo, Jaboticabal, 1997.

CARVALHO, P.C.F. O manejo da pastagem como gerador de ambientes pastoris adequados à produção animal. In: PEDREIRA, C.G.S.; MOURA, J.C.; SILVA, S.C. et al. (Eds.). Teoria e prática da produção animal em pastagens. Piracicaba: 2005. p.7-32.

CARVALHO, P.C.F.; RIBEIRO FILHO, H.M.N.; POLI, C.H.E.C. et al. Importância da estrutura da pastagem na ingestão e seleção de dietas pelo animal em pastejo In: A produção animal na visão dos brasileiros. 1.ed. Piracicaba: Fundação de Estudos Agrários Luiz de Queiroz, 2001a. p.853-871.

CARVALHO, P.C.F.; MARÇAL, G.K.; RIBEIRO FILHO, H.M.N. et al. Pastagens altas podem limitar o consumo dos animais In: REUNIÃOO ANUAL DA SOCIEDADE BRASILEIRA DE ZOOTECNIA, 38., 2001, Piracicaba. Anais... Piracicaba: Fundação de Estudos Agrários Luiz de Queiroz, 2001b. p.265266.

CARVALHO, P.C.F.; GONÇALVES, E.N.; POLI, C.H.E.C. et al. Ecologia do pastejo. In: Manejo estratégico da pastagem Viçosa, MG: Editora da UFV, 2006. p.43-72.

CARVALHO, P.C.F.; KOZLOSKI, G.V.; RIBEIRO FILHO, H.M.N. et al. Avanços metodológicos na determinação do consumo por ruminantes em pastejo. Revista Brasileira de Zootecnia, v.36, p.151-170, 2007.

CARVALHO, P.C.F.; GONDA, H.L.; WADE, M.H. et al. Características estruturais do pasto e o consumo de forragem: o quê pastar, quanto pastar e como se mover para encontrar o pasto In: Manejo estratégico da pastagem. Viçosa, MG: Editora UFV, 2008. v.1, p.101-130.

CARVALHO, P.C.F.; ANGHINONI, I.; MORAES, A. et al. Managing grazing animals to achieve nutrient cycling and soil improvement in no-till integrated systems. Nutrient Cycling in Agroecosystems (2009a - submet.).

CARVALHO, P.C.F.; MEZZALIRA, J.C.; FONSECA, L. et al. Do bocado ao sítio de pastejo: manejo em 3D para compatibilizar a estrutura do pasto e o processo de pastejo. SIMPOSIO DE FORRAGICULTURA E PASTAGEM, 7., 2009. Anais... 2009b (no prelo). 
CRUZ, P.; QUADROS, F.L.F.; THEAU, J.P. et al. Leaf traits as functional descriptors of the intensity of continuous grazing in native grasslands in the south of Brazil. Rangeland Ecology \& Management, 2009 (no prelo).

DERNER, J.D.; LAUENROTH, W.K.; STAPP, P. Livestock as ecosystem engineers for grassland bird habitat in the Western Great Plains of North America. Rangeland Ecology and Management, v.62, p.111-118, 2009

DITTRICH, J.R.; CARVALHO, P.C.F.; MORAES, A. et al. Comportamento ingestivo de eqüinos em pastejo sobre diferentes dosséis. Ciência Animal, v.8, p.87-94, 2007.

EDWARDS, G.E.; PARSONS, A.J.; BRYANT, R.H. Manipulating dietary preference to improve animal performance. Australian Journal of Experimental Agriculture, v.48, p.773-779, 2008.

GALLI, J.; CANGIANO, C.; DEMMENT, M. et al. Acoustic monitoring of chewing and intake of fresh and dry forages in steers. Animal Feed Science and Technology v.128, p.14$30,2006$.

GONÇALVES, E.N.; CARVALHO, P.C.F.; DEVINCENZI, T. et al. Relações planta-animal em ambiente pastoril heterogêneo: padrões de deslocamento e uso de estações alimentares. Revista Brasileira de Zootecnia, 2009a (no prelo).

GONÇALVES, E.N.; CARVALHO, P.C.F.; KUNRATH, T.R. et al. Relações planta-animal em ambiente pastoril heterogêneo: processo de ingestão de forragem. Revista Brasileira de Zootecnia, 2009b (no prelo).

HACKER, R.B.; THOMPSON, T.J.; MURRAY, W.K. et al. Precision pastoralism-advanced systems for management and integration of livestock and forage resources in the semi-arid rangelands in south easter Australia. In: Multifunctional grasslands and rangelands in a changing world. Beijing: Guangdong People's Publishing House, 2008. v.1, p.428-431.

HERVIEU, B. Multi-functionality: a conceptual framework for a new organization of research and development on grasslands and livestock systems. In: DURAND, J.L. et al. (Eds.) Multi-function grasslands : quality forages, animal products and landscapes. Grassland Science in Europe, 2002. v.7, p.1-4.

HODGSON, J.; CLARK, D.A.; MITCHELL, R.J. Foraging behavior in grazing animals and its impact on plant communities. In: FAHEY, G.C. (Ed.). Forage quality, evaluation and utilization. Lincoln: American Society of Agronomy, 1994. p.796-827.

LACA, E.A. Pastoreo de precisión. In: Bioma Campos: innovando para mantener su sustentabilidad y competitividad. Montevideo: Tradinco, 2008, v.1, p.29-40.

LACA, E.A. Precision livestock production: tools and concepts. Revista Brasileira de Zootecnia, 2009a (no prelo).

LACA, E.A. Running head: new tools for grazing management. Rangeland Ecology and Management, 2009b (no prelo).

LACA, E.A.; WALLIS DE VRIES, M.F. Acoustic measurement of intake and grazing behaviour of cattle. Grass and Forage Science, v.55, p.97-104, 2000.

LACA, E.A.; UNGAR, E.D.; SELIGMAN, N.G. et al. Effects of sward height and bulk density on bite dimensions of cattle grazing homogeneous swards. Grass and Forage Science, v.47, p.91$102,1992$.

LEMAIRE, G.; BENOIT, M.; VERTÈS, F. Rechercher de nouvelles organisations à l'échelle d'un territoire pour concilier autonomie protéique et préservation de l'environment.Fourrages, v.175, p.303-318, 2003.

MEZZALIRA, J.C.; NABINGER, C.; BREMM, C. et al. Filocrono de Paspalum notatum em função de diferentes ofertas de forragem em pastagem natural do sul do Brasil. In: REUNIÃO ANUAL DO GRUPO TÉCNICO EM FORRAGEIRAS DO CONE SUL - GRUPO CAMPOS, 2008, Minas. Anais... Minas, [2008]. (CD-ROM).

MEZZALIRA, J.C. O manejo do pastejo em ambientes pastoris heterogêneos: comportamento ingestivo produção animal em distintas ofertas de forragem. 2009. 159f. Dissertação (Mestrado em Zootecnia) - Faculdade de Agronomia/Universidade Federal do Rio Grande do Sul, Porto Alegre, 2009

MILONEA, D.H.; RUFINERA, H.L.; GALLI, J.R. et al. Computational method for segmentation and classification of ingestive sounds in sheep. Computers and Electronics in Agriculture, v.65, p.228-237, 2009.

PASCOA, A.G., COSTA, M.P. Aplicação dos sistemas de informação geográfica para definição de estratégias de manejo de bovinos em pastagens. Revista Brasileira de Zootecnia, v.36, p.45$51,2007$.

PENNING, P.D. Animal-based techniques for estimating herbage intake. In: PENNING, P.D. (Ed.). Herbage intake handbook. 2.ed. Reading: The British Grassland Society, 2004. p.53-94.

RIBEIRO FILHO, H.M.N. Nutrição de vacas leiteiras em pastagens de azevém perene: avaliação da introdução do trevo branco em função do manejo adotado no pastejo. $145 \mathrm{f}$. 2003. Tese (Zootecnia) - Universidade Federal do Rio Grande do Sul.

RUTTER, S.M. The integration of GPS, vegetation mapping and GIS in ecological and behavioural studies Revista Brasileira de Zootecnia, v.36, p.63-70, 2007

PALHANO, A.L.; CARVALHO, P.C.F.; DITTRICH, JR. et al. Características do processo de ingestão de forragem por novilhas holandesas em pastagens de capim-mombaça. Revista Brasileira de Zootecnia, v.36, p.1014-1021, 2007.

SILVA, S.C.; CARVALHO, P.C.F. Foraging behaviour and herbage intake in the favourable tropics/subtropics. In: Grassland: a global resource. 1.ed. Wageningen: Wageningen Academic Publishers, 2005. p.81-96.

SOARES, A.B.; CARVALHO, P.C.F.; GARCIA, E. et al. Herbage allowance and species diversity on native pasture. African Journal of Range and Forage Science, v.20, p.134-134, 2003.

TRINDADE, J.K.; SILVA, S.C.; CARVALHO, P.C.F. et al. Patterns of defoliation and selectivity of beef cattle during grazing of marandu palisadegrass subjected to strategies of rotational stocking. Grass and Forage Science (2009 - submetido)

UNGAR, E.D.; RUTTER, S.M. Classifying cattle jaw movements: comparing IGER Behaviour Recorder and acoustic techniques. Applied Animal Behaviour Science, v.98, p.11-27, 2006.

WADE, M.H. Factors affecting the availability of vegetative Lolium perenne to grazing dairy cows with special reference to sward characteristics, stocking rate and grazing method. 1991. 70f. Thése (Docteur en Sciences Biologiques) - U.F.R. Sciences de la vie et de l'environment, Université de Rennes, Rennes. 